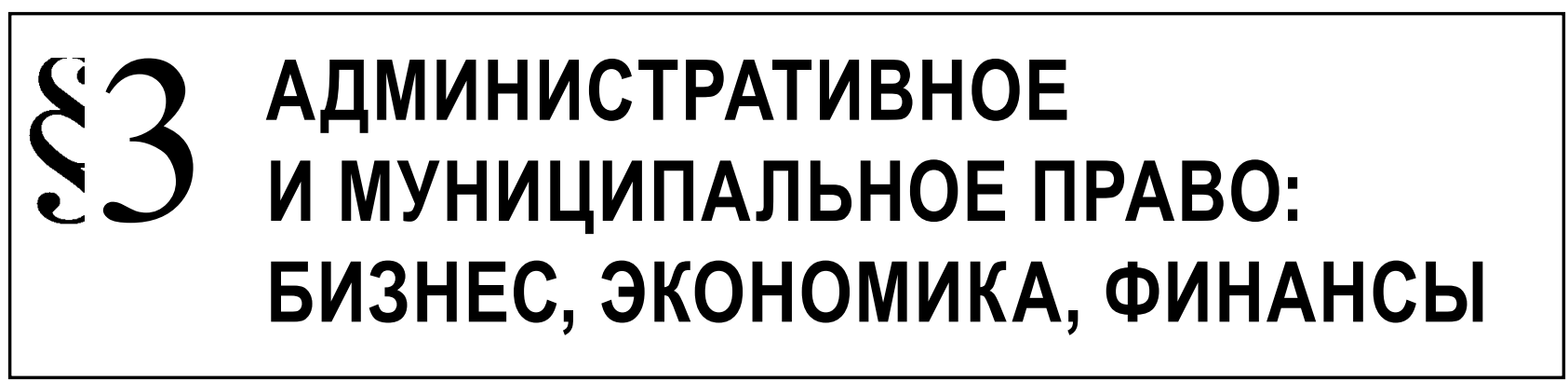

Колесников Ю.А.

\title{
ФИНАНСОВО-ПРАВОВОЙ СТАТУС СУБЪЕКТОВ РАСХОДНЫХ ОБЯЗАТЕЛЬСТВ И МЕХАНИЗМ УПРАВЛЕНИЯ БЮДЖЕТНЫМИ РЕСУРСАМИ
}

Аннотация: Предметом исследования в представленной статье является эффективность управления бюджетными ресурсами. Объектами исследования являются механизм управления бюджетными расходами, а также элементы «финансово-правового статуса»: полномочия (компетенции); обязанности; формы и методы реализации полномочий; гарантии осуществления полномочий. Целью работы является формулирование возможностей совершенствования механизма управления расходами бюджета. Автор подробно рассматривает такие аспекты, как опыт управления бюджетными ресурсами в унитарных и федеративных государствах, изучение понятия «финансово-правовой статус» через призму российского законодательства и теоретических исследований, обзор различных точек зрения по вопросу эффективности управления бюджетными расходами. Особое внимание уделяется правовым позициям Конституционного Суда РФ по анализируемому вопросу. Методологической основой исследования послужили общенаучные методы познания, такие как системный анализ и синтез, обобщение, группировка, аналогия и частнонаучные методы: монографический, статистико-экономический, расчетно-конструктивный. Новизна исследования заключается в выявлении проблем существующего механизма управления бюджетными расходами и предложении направлений по их оптимизации. Особым вкладом автора в исследование темы является обобщение различных точек зрения и предложений по вопросу эффективности управления бюджетными расходами и представление их в форме стратегии работы с бюджетными средствами. Практическая значимость исследования заключается в разработке научно обоснованных положений, выводов, рекомендаций по повышению эффективности управления бюджетными расходами. Полученные в исследовании результаты могут использоваться органами государственной власти всех уровней при разработке мер бюджетной, социальной политики в целях повышения эффективности бюджетных расходов и качества оказываемых бюджетных услуг.

Ключевые слова: бюджетные полномочия, субъекты РФ, финансово-правовой статус, бюджетные расходы, эффективность, государственные расходы, суверенитет бюджетов регионов, унитарные государства, местные бюджеты, конституционно-правовой статус.

Review: The subject of research in the presented article is the efficiency of budget resources management. The objects of the research are the mechanism of budget expenditures management and the elements of the financial-legal status: authorities (competences); responsibilities; forms and methods of exercise of authorities; guarantees of exercise of authorities. The aim of this work is the formulation of the possibilities for improving of the mechanism of budget expenditures contol. The author considers the experience of budget resources management in unitary and federal states, the study of the concept of "financial and legal status" through the prism of the Russian legislation and theoretical studies, an overview of different opinions on the issue of budget expenditures management efficiency. Special attention is paid to the legal positions of the Constitutional Court of the Russian Federation towards the analyzed issue.The methodology of the research is based on the methods of cognition, such as the system analysis and synthesis, generalization, grouping, analogy and the specific methods like the monographic method, the statistical and economical, the calculation and constructive method.The novelty of the research lies in identification of the problems of the existing mechanism of budget expenditures management and suggestion of directions of its optimization. The specific contribution of the author is the synthesis of different perspectives and proposals on the issue of budget expenditures management efficiency and 
their presenting in the form of a strategy of work with budgetary funds. The practical significance of the research lies in the creation of science-based regulations, conclusions and recommendations for improving of budget expenditures management. The results of the research can be used by public authorities at all levels for the development of fiscal and social policy in order to increase the efficiency of on-budget expenditures and the quality of budget services.

Keywords: the sovereignty of regional budgets, government spending, efficiency, budget expenditures, financial and legal status, subjects of the Russian Federation, budgetary authorities, unitary state, local budgets, constitutional and legal status.

$\prod$ онятие «государственные расходы», как известно, характеризуется многоплановостью. В Российской Федерации, в государстве федеративном, государственные расходы в числе прочего определяет наличие межбюджетных отношений как неотъемлемого элемента каждого федеративного государства. Качество и условия развития межбюджетных отношений являются важнейшими факторами как для устойчивости федерации, так и для экономической самодостаточности регионов - основы федерального бюджета.

Межбюджетные отношения при бюджетной системе, определяемой суверенитетом бюджетов регионов, имеют следующую схему: межбюджетное регулирование состоит в постоянном или временном распределении налоговых доходов между бюджетами разных уровней, либо в безвозмездном перераспределении средств из бюджетов одного уровня в другие в разных формах, что позволяет разграничивать межбюджетные расходы и доходы. Кроме того, межбюджетные отношения - это одна из основных возможностей урегулирования последствий неравенства, которое складывается в федеративном государстве как следствие естественной асимметрии субъектов федерации, в основе которой лежат резкие различия природно-климатических условий жизни, различия в характере осуществляемой предпринимательской деятельности, наличие (отсутствие) природных ресурсов, географическое положение субъекта федерации, имеющее влияние на его экономические связи с соседними регионами.

По мнению Ю.А. Беляева, каждая бюджетная система должна иметь направленность на достижение таких глобальных целей, как экономическая эффективность, социальная справедливость, политическая стабильность, господство закона и укрепление единства государства [8]. Устройство бюджета, равно как и предпочитаемая модель (концепция) управления бюджетными расходами, в каждом государстве зависит от существующей модели государственного устройства.

Так, унитарные государства имеют бюджетную систему, состоящую из двух звеньев: государственного бюджета и многочисленных местных бюджетов. Федеративные государства отличаются наличием бюджетной системы, состоящей или из двух, или из трех звеньев, что определяется наличием собственных предметов ведения в сфере местного самоуправления.

Во Франции, Китае, Украине, Белоруссии, рассматриваемых в качестве примеров унитарных государств, решение о распределении бюджетных средств принимается центральным правительством или его представителями различных уровней бюджетной системы. В таких государствах налоговыми полномочиями также наделен единый центр, все налоги становятся частью государственного бюджета, и впоследствии расходование средств происходит в соответствии с едиными стандартами и нормативами.

В противоположность унитарным, в государстве федеративном местные бюджеты обладают определенной степенью самостоятельности в финансово-правовой сфере, что выступает в качестве определенного стимула для их экономического развития. Все федеративные государства характеризуются наличием схемы разграничения предметов ведения и полномочий, кроме того, субъекты федерации обладают собственной компетенцией. Как результат можно обозначить присвоение субъектам федерации собственного финансово-правового статуса наряду с всегда присутствующим конституционно-правовым [10].

К вопросу об определении понятия конституционно-правового статуса (положения) субъектов обращались авторы многих научных работ. Основной интерес для большинства представляет определение конституционно-правового статуса, рассматриваемого сквозь призму его юридического закрепления.

Правовой статус представляет собой базовую категорию, характеризующую все субъекты Российской Федерации. Правовой статус субъекта понятие, включающее в себя и финансово-правовой статус, и территориально-правовой статус, и историческое наследие. Особый интерес представляет фактическое положение субъектов, и прежде всего их финансово-правовые полномочия. 
Финансовые права и обязанности субъектов определяются их финансово-правовым положением. Одним из первых исследователей, осуществивших комплексную разработку финансовоправового положения субъектов, является Ю.Л. Смирникова [16]. В ее определении финансовоправовой статус субъектов Российской Федерации является правовым положением субъектов Федерации в случаях финансовых правоотношений при их участии, что, иными словами, представляет собой совокупность прав и обязанностей, конкретизирующую финансово-правовые предметы ведения и полномочия (финансовая компетенция субъектов Федерации).

Понятие финансово-правового статуса должно определяться исходя из того, что действия субъектов Российской Федерации не являются непосредственными, они осуществляются системой образуемых ими органов государственной власти. Таким образом, финансовые полномочия субъектов оказываются сведены к компетенции их органов. Опираясь на вышеизложенное, возможно выделить такие элементы финансово-правового статуса, как, во-первых, наличие полномочий (компетенций), конституционно закрепленных за субъектами Российской Федерации. Одновременно с этим полномочия субъектов федерации в финансовой сфере уточняются и развиваются посредством осуществления текущего законотворчества субъектов, которые наделяют свои органы определенной компетенцией. Во-вторых, обращает на себя внимание необходимость определения обязанностей, которые корреспондируют с предоставленными полномочиями, поскольку основное ядро правового статуса субъектов федерации составляется из полномочий субъектов федерации и их обязанностей. В-третьих, выделяются формы и методы реализации полномочий. Наконец, в-четвертых, выступают гарантии осуществления предоставленных полномочий.

Равенство правомочий субъектов Российской Федерации закреплено на уровне Конституции. Согласно п. 4. ст. 5 Конституции Российской Федерации [1] все субъекты Российской Федерации равноправны во взаимоотношениях с федеральными органами государственной власти. Равенством правомочий предполагаются и равные гарантии их реализации.

Однако существуют некоторые отличия официальной позиции федерации от вышеназванной конституционной нормы. Согласно правовой позиции Конституционного Суда Российской Феде- рации, сформулированной им в Постановлении от 15 июля 1996 года № 16-П [3], правовое равенство субъектов Российской Федерации не предполагает равенства их потенциалов и уровня социально-экономического развития, которые зависят от территории, географического положения, численности населения, исторически сложившейся структуры народного хозяйства и т.д. Соблюдение баланса интересов и внедрение общегосударственных стандартов во всех сферах жизнедеятельности субъектов Российской Федерации возможно только при условии учета региональных особенностей.

Конституционный Суд Российской Федерации, разрабатывая вопросы, связанные с содержанием финансово-правового статуса субъектов Российской Федерации и закрепленными конституционно границами их самостоятельности в сфере финансово-бюджетных отношений, сформулировал правовую позицию, в соответствии с которой в силу статьи 73 Конституции Российской Федерации субъекты Российской Федерации наделены всей полнотой государственной власти вне пределов ведения и полномочий Российской Федерации по предметам совместного ведения Российской Федерации и ее субъектов, а именно, они имеют право управления своей собственностью, право на наличие у них собственного бюджета и самостоятельное осуществление бюджетного процесса. Бюджетная самостоятельность Российской Федерации, субъектов Российской Федерации и муниципальных образований определяется согласно их статусу, установленному непосредственно Конституцией Российской Федерации, ее статьями 5, 10, $11,12,65$ и 132 (Постановление от 11 ноября 2003 года №16-П [3], Определение от 8 января 1998 года №4-0) [4]. Наряду с этим реализация бюджетной самостоятельности субъектов Российской Федерации в любом случае осуществляется ими согласно конституционным принципам функционирования бюджетной системы Российской Федерации как единой системы, которая предназначена для эффективного распределения и перераспределения финансовых ресурсов, благодаря чему возможно финансовое обеспечение функций, осуществляемых на каждом из уровней публичной власти в Российской Федерации.

Финансовое регулирование, федеральный бюджет и федеральные фонды регионального развития являются предметами ведения Российской Федерации (статья 71, пункты «ж», «з» Конституции Российской Федерации) [1]. В связи с неизолированностью бюджетов субъектов Российской 
Федерации и местных бюджетов, т.к. они представляют собой часть финансовой системы Российской Федерации, в случае недостаточности собственных доходов субъектов Российской Федерации или муниципальных образований возникает необходимость бюджетного регулирования для достижения баланса соответствующих бюджетов. Это осуществляется путем дотаций из федерального бюджета бюджетам субъектов Российской Федерации.

Как уже упоминалось выше, конкретизация финансово-правового статуса субъектов происходит за счет определения предметов ведения и полномочий. Изучая конституционные нормы, которые разграничивают предметы ведения как Российской Федерации, так и субъектов Российской Федерации, исследователи сходятся во мнении, что предметы ведения Конституция РФ определяет как сферу общественных отношений, которые подлежат правовому регулированию, разграничивая правовое поле между РФ и субъектами. Затем в рамках данного правового поля следует разграничение федеральным и региональным законодателем исполнительной и судебной компетенции в пределах конституционно закрепленных предметов ведения.

Анализируя Конституцию РФ по вопросу более четкого определения рассмотренных выше понятий, следует отметить, что рассмотрение ст. 71, 72 и 73 Конституции РФ не позволяет однозначно сказать, что следует определять как предметы ведения [1]. В нормах указанных статей в качестве предметов ведения могут быть упомянуты сферы, области, отрасли государственного управления, отдельные виды деятельности, функции. Если рассматривать предметы ведения исходя из того, что закреплено в названных статьях Конституции РФ, возникает неясность в разграничении понятий «компетенция», «предметы ведения» и «полномочия». Не следует также смешивать понятие «предметы ведения» с их конкретными видами (частным выражением предметов ведения). Кроме того, в правовой системе России встречается такой вид предметов ведения, как полномочия. К примеру, в п. «а» ст. 71 Конституции к ведению Российской Федерации отнесено «принятие и изменение Конституции Российской Федерации и федеральных законов» [1]. Полномочия, рассматриваемые в качестве вида предметов ведения, отличны от полномочий, рассматриваемых как содержание компетенции органа государственной власти. Основное значение наделения Российской Федерации полномочием принятия и изменения Конституции и федеральных законов состоит в том, что это прерогатива Федерации, а не в том, чтобы наделить данным полномочием конкретный орган. Исследование норм Конституции РФ позволяет говорить именно о таком соотношении понятий «компетенция», «предметы ведения» и «полномочия».

Для разрешения проблемы следует исходить из следующих положений. Государственная власть реализуется между ее участниками в законодательно определенном объеме. Данный объем предопределяет совокупность правовых, организационных и финансово-экономических механизмов реализации власти. Объективное существование различных сфер жизнедеятельности общества предполагает наличие круга вопросов, решение которых в целом обеспечивает достижение задач и осуществление функций, стоящих перед Российским государством. Вопросы, составляющие ту или иную сферу общественной жизни, распределяются между Российской Федерацией, субъектами РФ, местным самоуправлением в зависимости от правосубъектности соответствующего уровня в федеративной системе государственного устройства. Таким образом, предметы ведения выступают элементом характеристики статуса территориального образования.

Изучая действующее законодательство, возможно прийти к выводу о том, что ни одна из конкретных сфер или областей государственного управления не может быть названа исключительным предметом ведения РФ или субъекта РФ. Представляется невозможным рассмотрение в качестве предметов ведения также материальных объектов, финансово-денежных средств, государственных и иных институтов, органов, организаций, руководителей и должностных лиц, поскольку они представляют собой объекты управляющего воздействия в процессе государственного управления и регулирования. Правовые акты и юридические действия являют собой одну из форм деятельности органов исполнительной власти, связанную с реализацией предоставленных полномочий.

Конституционные предметы ведения, установленные в ст. 71 и 72 [1], в действительности являются областями приложения законодательной, исполнительной, судебной власти. Каждая ветвь власти, несомненно, имеет свое поле деятельности. Законодательная, исполнительная и судебная власть способствуют решению задач, которые стоят перед государственной властью в целом, посредством выполнения возложенных на них функций. Не рассматривая сферы деятельности законодательной и 
судебной власти, отметим, что поле деятельности исполнительной власти - это управление в его узком значении. Объектами государственного управления в узком его понимании выступают сферы, области, отрасли - оборона, образование, здравоохранение, экономика и т.д. Поэтому можно сказать, что предмет ведения исполнительной власти - это объекты государственного управления.

В этой связи под предметами ведения РФ, субъектов РФ необходимо подразумевать конституционно установленные вопросы Российской Федерации, субъектов РФ, вопросы совместного ведения РФ и ее субъектов самоуправления в соответствующих сферах общественной жизни. Таким образом, финансово-правовой статус каждого субъекта индивидуально устанавливается федерацией исходя из законодательно закрепленных предметов ведения и полномочий. Отметим, что существует риск нарушения принципа равенства и возможности предоставления преференций одним субъектам перед другими при таком индивидуальном подходе.

Следствием этого можно назвать необходимость корректировки механизма определения финансово-правового статуса субъектов Российской Федерации. Принцип равенства субъектов должен соблюдаться посредством изменения статуса финансовой помощи федерации, которая должна не компенсировать разрыв в доходах субъектов, а помогать в развитии экономической составляющей.

Кроме того, финансово-правовой статус субъектов Российской Федерации устанавливается и исходя из совокупности их государственных полномочий в вопросах бюджетных расходов. В отношении механизма управления бюджетными расходами в федеративном государстве с ярко выраженной асимметрией (примером которого и является Российская Федерация) существуют несколько подходов.

Например, Борисовым А.Н. выделяются две концепции бюджетных расходов [9]: концепция управления ресурсами и концепция управления результатами. В рамках концепции «управление ресурсами» формирование бюджета происходит путем индексации сложившихся расходов с детальной разбивкой их по статьям бюджетной классификации РФ. Такой подход помогает в достижении сбалансированности бюджета и выполнении бюджетных проектировок. Однако таким образом управление бюджетом сводится в основном к контролю соответствия фактических и плановых показателей. В рамках концепции «управление результатами» формирование бюджета происходит в соответствии с целями и планируемыми результатами государственной политики. При планировании бюджетных ассигнований основные требования состоят в обосновании конечных результатов по бюджетным программам. Приветствуется расширение самостоятельности и ответственности администраторов бюджетных средств, что проявляется в установлении долгосрочных переходящих лимитов ассигнований с их ежегодной корректировкой, формировании общей суммы ассигнований (глобального бюджета) для выполнения определенных функций и программ, детализации направлений использования бюджетных средств, которое производится администраторами, приоритет имеет внутренний контроль, ответственность за принятие решений возлагается на нижние уровни.

Необходимость повышения эффективности бюджетных расходов вытекает из установленного Президентом и Правительством Российской Федерации курса на модернизацию страны, который вызвал объективную потребность совершенствования бюджетной политики и бюджетных инструментов регулирования с целью обеспечения инновационного развития экономики страны. Основой реорганизации бюджетного процесса должна стать такая концепция бюджетирования, которая будет ориентирована на результаты в рамках среднесрочного финансового планирования, она широко применяется в мире. Суть ее состоит в распределении бюджетных ресурсов между администраторами бюджетных средств и (или) бюджетными программами, принимая во внимание конкретные результаты, ориентируясь на среднесрочные приоритеты социально-экономической политики и пределы прогнозируемых объемов бюджетных ресурсов в долгосрочной перспективе.

Две модели осуществления бюджетных расходов выделяются и Сильвестровой Т.М.: это результативная модель и затратная модель [15]. Результативная модель управления бюджетными средствами предполагает самостоятельность принятия решений получателями бюджета и позволяет продуктивно оценить результаты их работы, т.к. результативная модель управления бюджетными средствами основывается на наличии плановых и фактических показателей.

Основной характеристикой затратной модели управления бюджетными средствами является отсутствие самостоятельности получателей бюджета в процессе расходования ими бюджетных ассигнований. Оценка эффективности расходования бюджетных средств в рамках затратной модели 
предполагает сложности, связанные с отсутствием законодательно установленных предполагаемых результатов деятельности. Но несмотря на недостатки, данная модель считается очень стабильной, т.к. привычна и удобна как для главных распорядителей, так и для получателей бюджетных средств; она не предполагает доверия к получателям бюджета, поскольку им предоставляется ограниченный круг полномочий.

Кроме описанных выше концепций управления бюджетными ресурсами, существует и множество иных, в качестве примеров которых можно привести следующие.

К примеру, Уманец О.П. предлагает модель социализации и планирования расходов федерального бюджета посредством применения метода целевого управления бюджетными средствами [17]. Суть данной модели состоит в осуществлении планирования бюджетных расходов на федеральном уровне в форме федеральных целевых программ. Целевое управление бюджетными средствами представляется основным методом планирования и исполнения бюджетных расходов в условиях социального государства. В более широком смысле «целевое управление» может пониматься в качестве технологии и методологии реализации интересов социального государства исходя из его социальных обязательств, приоритетов и возможностей. Нормативный подход, направленный на правовое обеспечение планирования и контрольно-регулирующих мер по соблюдению социальных нормативов и нормативов, предусматривающих мероприятия по улучшению условий труда и охране окружающей среды, призван обеспечить сбалансированность решений для продуктивного исполнения расходов и успешной реализации целевых программ.

Отличительной особенностью целевого управления бюджетными средствами от ориентированного на результат бюджетирования можно назвать то, что им не предполагаются особые условия для планирования, нет зависимости от прогнозов, обеспечен мониторинг изменений в режиме реального времени и возможна реализация автоматизации процессов на всех уровнях исполнения бюджета в вопросах, затрагивающих направления расходов или целевые программы, учитывается их социальная направленность.

Белов А.В., формулируя свое представление о концепции осуществления бюджетных расходов, отмечает, что в Российской Федерации сложилась концепция «централистского федерализма» [7]. Основные ее черты заключаются в централизации доходов и регионализации расходов, циклических колебаниях бюджетных поступлений и ассигнований, а также в жесткой регламентации федеральными властями доходной и расходной деятельности региональных и местных органов. Для повышения эффективности бюджетных расходов представляется необходимым более активное использование бюджетной политики в интересах развития экономики и решения приоритетных социальных задач; совершенствование бюджетной системы страны с целью усиления ее влияния на экономику и социальную сферу; проведение бюджетной политики, ориентированной на реальные результаты благодаря определению ее эффективности, а также обеспечение бюджетной стабильности.

Формулируя свои выводы по вопросу концепции повышения бюджетных расходов муниципальных образований, Ярошенко Т.П. говорит о комплексности понятия эффективности бюджетных расходов [19]. По ее мнению, главными составляющими данного понятия можно назвать экономичность, продуктивность и результативность.

На достижение описанных выше составляющих понятия эффективности бюджетных расходов нацелена и системная концепция повышения эффективности государственного управления бюджетными ресурсами, разработанная А.В. Комаровой [12]. Данная концепция состоит в следующем: существует необходимость выявления того, есть ли у казначейства потенциал для повышения эффективности управления бюджетными средствами за счет переориентирования его деятельности в соответствии со специфическими критериями эффективности и создание необходимых для их достижения условий, а также гармонизации и расширения функций казначейства, учитывая его двойное подчинение Министерству финансов и органам представительной власти, также необходимо обосновать и реализовать его активную роль в управлении и достижении предельной производительности использования бюджетных ресурсов.

Реализация описанной системной концепции представляется возможностью обеспечения последовательного перехода в первую очередь к унифицированной системе управления исполнением всех видов бюджета, следующим шагом нужно внедрить инструменты и методы управления предельной производительностью использования бюджетных средств, завершающим этапом станет гармонизация в сочетании исполнения уже принятого бюджета и стратегического управления бюджетными ресурсами. 


\section{Библиография:}

1. Конституция Российской Федерации от 12 декабря 1993 года.

2. Постановление Конституционного Суда РФ от 15.07.1996 № 16-П «По делу о проверке конституционности пункта 1 статьи 1 и пункта 4 статьи 3 Закона РФ от 18 октября 1991 года «О дорожных фондах в РФ» // Российская газета, № 136, 20.07.1996.

3. Постановление Конституционного Суда РФ от 11.11.2003 № 16-П «По делу о проверке конституционности положений пункта 2 статьи 81 Закона Челябинской области «О бюджетном устройстве и бюджетном процессе в Челябинской области» в связи с запросом Челябинского областного суда» // Российская газета, № 233, 18.11.2003.

4. Определение Конституционного Суда РФ от 08.01.1998 № 4-О «Об отказе в принятии к рассмотрению жалобы гражданина Мордясова С.Н. на нарушение его конституционных прав ст. 97 УПК РСФСР» // www.ksrf.ru

5. Бюджетный Кодекс РФ от 31.07.1998 № 145-Ф3 (ред. от 29.11.2014) // www.consultant.ru

6. Авдийский В.И., Павликов С.Г. О соотношении экономики и права и тенденциях конституционно-правового регулирования экономических отношений. // Государство и право, 2014, № 11.

7. Белов А.В. Инструменты и методы формирования эффективной бюджетной политики. Автореферат диссертации на соискание ученой степени доктора экономических наук. - Москва, 2010.

8. Беляев Ю.А. Проблемы и практика казначейского исполнения бюджета муниципального образования. // Финансы, 1999, № 11.

9. Борисов А.Н. Комментарий к Бюджетному кодексу РФ (постатейный) (издание второе, переработанное и дополненное). - «Юстицинформ», 2008.

10. Бюджетное право: учебное пособие / под ред. М.В. Карасевой. - М.: Эксмо, 2010. - 320 с.

11. Васянина Е.Л. К вопросу об эффективности управления государственными доходами. // Финансовое право, 2014, № 9.

12. Комарова А.В. Роль казначейства в повышении эффективности государственного управления бюджетными средствами. Автореферат диссертации на соискание ученой степени кандидата экономических наук. Ростов-наДону, 2006.

13. Нуриахметов Н.М. О понятии бюджетной деятельности Государства. // Финансовое право, 2014, № 10.

14. Протасовицкий С.П. Понятие финансов: новая парадигма. // Государство и право, 2014, № 12.

15. Сильвестрова Т.М. Критерии оценки эффективности использования эффективных средств при современной модели управления бюджетными ресурсами. // Бюджетные организации: бухгалтерский учет и налогообложение, 2013, № 11.

16. Смирникова Ю.Л. Финансово-правовой статус субъекта Российской Федерации // Журнал российского права, № 6, 2002.

17. Уманец О.П. Управление доходами и расходами федерального бюджета России в условиях социального государства: диссертация ... кандидата экономических наук. - Москва, 2010.

18. Финансовый механизм и право: монография / отв. ред. С.В. Запольский. - М.: КОНТРАКТ, $2014 .-248$ с.

19. Ярошенко Т.П. Методическое развитие оценки эффективности бюджетных расходов муниципального образования: диссертация ... кандидата юридических наук. - Сургут, 2011.

\section{References (transliterated):}

1. Konstitutsiya Rossiiskoi Federatsii ot 12 dekabrya 1993 goda.

2. Postanovlenie Konstitutsionnogo Suda RF ot 15.07.1996 № 16-P «Po delu o proverke konstitutsionnosti punkta 1 stat'i 1 i punkta 4 stat'i 3 Zakona RF ot 18 oktyabrya 1991 goda «O dorozhnykh fondakh v RF» // Rossiiskaya gazeta, № 136, 20.07.1996.

3. Postanovlenie Konstitutsionnogo Suda RF ot 11.11.2003 № 16-P «Po delu o proverke konstitutsionnosti polozhenii punkta 2 stat'i 81 Zakona Chelyabinskoi oblasti «O byudzhetnom ustroistve i byudzhetnom protsesse v Chelyabinskoi oblasti» v svyazi s zaprosom Chelyabinskogo oblastnogo suda» // Rossiiskaya gazeta, № 233, 18.11.2003.

4. Opredelenie Konstitutsionnogo Suda RF ot 08.01.1998 № 4-0 «Ob otkaze v prinyatii k rassmotreniyu zhaloby grazhdanina Mordyasova S.N. na narushenie ego konstitutsionnykh prav st. 97 UPK RSFSR» // www.ksrf.ru

5. Byudzhetnyi Kodeks RF ot 31.07.1998 № 145-FZ (red. ot 29.11.2014) // www.consultant.ru

6. Avdiiskii V.I., Pavlikov S.G. O sootnoshenii ekonomiki i prava i tendentsiyakh konstitutsionno-pravovogo regulirovaniya ekonomicheskikh otnoshenii. // Gosudarstvo i pravo, 2014, № 11.

7. Belov A.V. Instrumenty i metody formirovaniya effektivnoi byudzhetnoi politiki. Avtoreferat dissertatsii na soiskanie uchenoi stepeni doktora ekonomicheskikh nauk. - Moskva, 2010.

8. Belyaev Yu.A. Problemy i praktika kaznacheiskogo ispolneniya byudzheta munitsipal'nogo obrazovaniya. // Finansy, 1999, № 11.

9. Borisov A.N. Kommentarii k Byudzhetnomu kodeksu RF (postateinyi) (izdanie vtoroe, pererabotannoe i dopolnennoe). «Yustitsinform», 2008. 
10. Byudzhetnoe pravo: uchebnoe posobie / pod red. M.V. Karasevoi. - M.: Eksmo, 2010. - 320 s.

11. Vasyanina E.L. K voprosu ob effektivnosti upravleniya gosudarstvennymi dokhodami. // Finansovoe pravo, 2014 , № 9.

12. Komarova A.V. Rol' kaznacheistva v povyshenii effektivnosti gosudarstvennogo upravleniya byudzhetnymi sredstvami. Avtoreferat dissertatsii na soiskanie uchenoi stepeni kandidata ekonomicheskikh nauk. Rostov-na-Donu, 2006.

13. Nuriakhmetov N.M. O ponyatii byudzhetnoi deyatel'nosti Gosudarstva. // Finansovoe pravo, 2014 , № 10.

14. Protasovitskii S.P. Ponyatie finansov: novaya paradigma. // Gosudarstvo i pravo, 2014, № 12.

15. Sil'vestrova T.M. Kriterii otsenki effektivnosti ispol'zovaniya effektivnykh sredstv pri sovremennoi modeli upravleniya byudzhetnymi resursami. // Byudzhetnye organizatsii: bukhgalterskii uchet i nalogooblozhenie, 2013 , № 11.

16. Smirnikova Yu.L. Finansovo-pravovoi status sub"ekta Rossiiskoi Federatsii // Zhurnal rossiiskogo prava, № 6, 2002.

17. Umanets O.P. Upravlenie dokhodami i raskhodami federal'nogo byudzheta Rossii v usloviyakh sotsial'nogo gosudarstva: dissertatsiya ... kandidata ekonomicheskikh nauk. - Moskva, 2010.

18. Finansovyi mekhanizm i pravo: monografiya / otv. red. S.V. Zapol'skii. - M.: KONTRAKT, 2014. - $248 \mathrm{~s}$.

19. Yaroshenko T.P. Metodicheskoe razvitie otsenki effektivnosti byudzhetnykh raskhodov munitsipal'nogo obrazovaniya: dissertatsiya ... kandidata yuridicheskikh nauk. - Surgut, 2011. 